\title{
Commentary \\ 'Relation, association, attribution ...' - the multiple faces of death in critical care medicine
}

\author{
Susanne Toussaint and Herwig Gerlach
}

\author{
Department of Anesthesia, Intensive Care Medicine, and Pain Management, Vivantes - Klinikum Neukölln, Rudower Strasse 48, D-12313 Berlin, \\ Germany
}

Corresponding author: Herwig Gerlach, herwig.gerlach@vivantes.de

Published: 29 April 2009

Critical Care 2009, 13:138 (doi:10.1186/cc7789)

This article is online at http://ccforum.com/content/13/2/138

(c) 2009 BioMed Central Ltd

See related research by Melamed and Sorvillo, http://ccforum.com/content/13/1/R28

\begin{abstract}
Mortality is one of the most important quality markers in critical care, and there have been many epidemiological studies trying to identify risk factors to better understand the mechanisms leading to death in this complex disease. One of the major problems is that there are multiple factors contributing to fatal outcome of septic patients, and it is difficult to distinguish between those that are independent from the acute disease (comorbidities and 'risk factors') and those that are directly involved in the pathomechanisms of sepsis, thus leading to the 'sepsis-attributable' mortality. In this short commentary, some examples of different approaches of how to analyze data on mortality are presented.
\end{abstract}

Easy to detect, but difficult to interpret - a simple approach to one of the most important quality markers in critical care medicine: mortality. In a recent issue of Critical Care, this was impressively demonstrated by Melamed and Sorvillo [1], who analyzed a huge multiple-cause-of-death (MCOD) database in the US with the aim of investigating factors affecting mortality in septic patients. The investigators showed that there are numerous disparities between patients, and these have to be considered when mortality rates are interpreted. Gender, age, and ethnicity are factors that have considerable influence on the outcome of septic patients, and crude mortality over time differs from age-adjusted values. Moreover, the authors conclude that the epidemiology of sepsis should be studied individually in racial/ethnic minorities so as to elucidate unique features in each group [1].

Although these results - on first view - may not be that surprising since there are a couple of studies showing similar results regarding the effect of confounding factors like gender and age on the mortality of sepsis [2], the paper of Melamed and Sorvillo [1] is another important contribution to improving our understanding of why septic patients die and how time-dependent the developments are [3]. However, is this approach clear and well defined? In terms of methods of how data were analyzed, definitely yes! Limitations due to the structure of the database were thoroughly discussed by the investigators, and conclusions were critically reviewed with respect to existing literature. But there is another aspect that should be pointed out by this short commentary: the way that 'sepsis-related' and/or 'sepsis-associated' mortality is defined. Relation and association are not very precise attributes; they simply consider that the death of a patient has something to do with sepsis. There are two major approaches of how these 'crude' data can be analyzed to give a clearer picture of the complex mechanisms in severe sepsis and to allow us to conclude what might be the reasons why septic patients do not survive.

The 'multiple-cause-of-death' analysis is one of these ways, and actually it is the method with which most epidemiological studies in septic patients are designed. The aim is always to assess, by different statistical methods such as multiple logistic regressions or propensity scoring, the risk factors that affect the outcome of septic patients. The other way is much more difficult: it tries to describe how mortality of critically ill patients is influenced by the fact that they are septic. These forms of analyses are rarely found in the literature, although terms like 'sepsis-attributed' or 'sepsis-attributable' or 'excess' mortality are often used. However, the attributable mortality in general defines the mortality directly associated with sepsis and apart from the mortality attributable to underlying conditions. A simple example: to analyze whether obesity per se is a risk factor for dying in an intensive care unit (ICU), investigators would have to perform a matched case control study that compared patients with similar course, but without obesity. Using this method, Bercault and colleagues [4] demonstrated that obesity is an independent

$\mathrm{ARF}=$ acute renal failure; $\mathrm{ICU}=$ intensive care unit. 
risk factor for mortality in the ICU. Not only comorbidities, but also events may be analyzed such as shown by Classen and colleagues [5], who proved that adverse drug events are associated with a significantly prolonged length of stay, increased economic burden, and an almost twofold increased risk of death. Two other examples: in women younger than 65 , influenza was shown to increase mortality substantially [6], and critically ill patients with liver cirrhosis suffering from additional acute renal failure (ARF) have a mortality of $65 \%$, and those without ARF have a mortality 32\% [7] (that is, the 'excess mortality' of ARF in this subgroup is roughly 33\%).

In regard to infections, some studies demonstrate what is generally expected: candidemia in hospitalized patients is associated with excess mortality rates of $10.0 \%$ in children and $14.5 \%$ in adults [8]. Other studies report a candidemiaassociated excess risk to die in hospital of $19 \%$ to $24 \%$ [9]. In the ICU, catheter-related infections have been analyzed showing contradictory results, either with a significant excess mortality (24.6\%) from a study in Argentina [10] or with just a trend after adjustment of other severity factors from a study in France [11]. Some studies have surprising results: Blot and colleagues [12] demonstrated that nosocomial Escherichia coli bacteremia in critically ill patients had no excess mortality after adjustment for disease severity! Overall, nosocomial bloodstream infections seem to be associated with an intrinsic excess mortality. In critically ill HIV patients, Tumbarello and colleagues [13] assessed a crude mortality of $43 \%$, with an infection-associated excess mortality of $27 \%$. A similar rate of bloodstream infection-associated excess mortality (28\%) was described by Smith and colleagues [14] in non-HIV patients. Probably one of the largest investigations was presented by Pittet and colleagues [15], who found a crude mortality of $50 \%$ in critically ill patients with infections versus $15 \%$ without infections (that is, the attributable mortality was 35\%).

How are the results for sepsis or severe sepsis defined as inflammatory response plus infection (plus organ dysfunction in severe sepsis)? Very simple: unknown! So far, there are no existing data that enable us to attribute an 'excess mortality' to sepsis, probably due to the fact that not only the complex disease but also the difficult definition of sepsis prevents us from separating crude from excess mortality. We should keep this in mind when we try to interpret results from epidemiological studies on sepsis. Hopefully, extended statistical methods and the use of large registries similar to the presented database [1] will help us to overcome this burden in the future.

\section{Competing interests}

The authors declare that they have no competing interests.

\section{References}

1. Melamed A, Sorvillo FJ: The burden of sepsis-associated mortality in the United States from 1999 to 2005: an analysis of multiple-cause-of-death data. Crit Care 2009, 13:R28.
2. Dombrovskiy VY, Martin AA, Sunderram J, Paz HL: Rapid increase in hospitalization and mortality rates for severe sepsis in the United States: a trend analysis from 1993 to 2003. Crit Care Med 2007, 35:1244-1250.

3. Christaki E, Opal SM: Is the mortality rate for septic shock really decreasing? Curr Opin Crit Care 2008, 14:580-586.

4. Bercault N, Boulain T, Kuteifan K, Wolf M, Runge I, Fleury JC: Obesity-related excess mortality rate in an adult intensive care unit: a risk-adjusted matched cohort study. Crit Care Med 2004, 32:998-1003.

5. Classen DC, Pestotnik SL, Evans RS, Lloyd JF, Burke JP: Adverse drug events in hospitalized patients: excess length of stay, extra costs, and attributable mortality. JAMA 1997, 277:301-306.

6. Neuzil KM, Reed GW, Mitchel EF, Griffin MR: Influenza-associated morbidity and mortality in young and middle-aged women. JAMA 1999, 281:901-907.

7. Du Cheyron D, Bouchet B, Parienti JJ, Ramakers M, Charbonneau $P$ : The attributable mortality of acute renal failure in critically ill patients with liver cirrhosis. Intensive Care Med 2005, 31: 1693-1699.

8. Zaoutis TE, Argon J, Chu J, Berlin JA, Walsh TJ, Feudtner C: The epidemiology and attributable outcomes of candidemia in adults and children hospitalized in the United States: a propensity analysis. Clin Infect Dis 2005, 41:1232-1239.

9. Morgan J, Meltzer MI, Plikaytis BD, Sofair AN, Huie-White S, Wilcox S, Harrison LH, Seaberg EC, Hajjeh RA, Teutsch SM: Excess mortality, hospital stay, and cost due to candidemia: a case-control study using data from population-based candidemia surveillance. Infect Control Hosp Epidemiol 2005, 26: 540-547.

10. Rosenthal VD, Guzman S, Migone O, Crnich CJ: The attributable costs, length of hospital stay, and mortality of central line-associated bloodstream infection in intensive care departments in Argentina: a prospective, matched analysis. Am J Infect Control 2003, 31:475-480.

11. Soufir L, Timsit JF, Mahe C, Carlet J, Regnier B, Chevret S: Attributable morbidity and mortality of catheter-related septicaemia in critically ill patients: a matched, risk-adjusted, cohort study. Infect Control Hosp Epidemiol 1999, 20:396-401.

12. Blot S, Vandewoude K, Hoste E, De Waele J, Kint K, Rosiers F, Vogelaers D, Colardyn F: Absence of excess mortality in critically ill patients with nosocomial Escherichia coli bacteremia. Infect Control Hosp Epidemiol 2003, 24:912-915.

13. Tumbarello M, Tacconelli E, Donati KG, Leone F, Morace G, Cauda R, Ortona L: Nosocomial bloodstream infections in HIV-infected patients: attributable mortality and extension of hospital stay. J Acquir Immun Defic Syndr Hum Retrovirol 1998, 19:490-497.

14. Smith RL, Meixler SM, Simberkoff MS: Excess mortality in critically ill patients with nosocomial bloodstream infections. Chest 1991, 100:164-167.

15. Pittet D, Tarara D, Wenzel RP: Nosocomial bloodstream infections in critically ill patients: excess length of stay, extra costs, and attributable mortality. JAMA 1994, 271:1598-1601. 